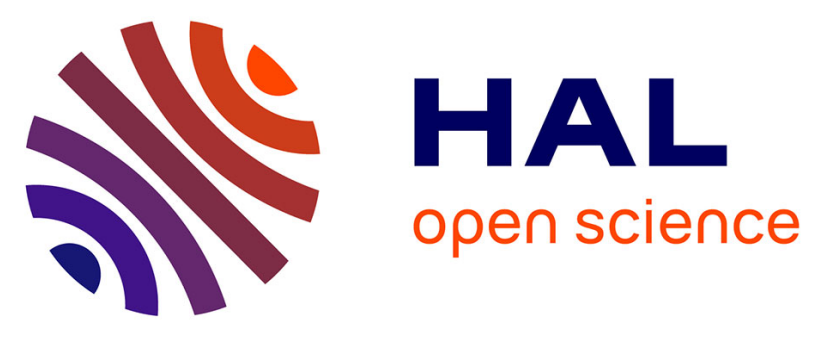

\title{
Body-size shifts in aquatic and terrestrial urban communities
}

Thomas Merckx, Caroline Souffreau, Aurélien Kaiser, Lisa F Baardsen, Thierry Backeljau, Dries Bonte, Kristien I Brans, Marie Cours, Maxime Dahirel, Nicolas Debortoli, et al.

\section{To cite this version:}

Thomas Merckx, Caroline Souffreau, Aurélien Kaiser, Lisa F Baardsen, Thierry Backeljau, et al.. Body-size shifts in aquatic and terrestrial urban communities. Nature, 2018, 558 (7708), pp.113-116. 10.1038/s41586-018-0140-0 . hal-01807844

HAL Id: hal-01807844 https://hal-univ-rennes1.archives-ouvertes.fr/hal-01807844

Submitted on 3 Sep 2018

HAL is a multi-disciplinary open access archive for the deposit and dissemination of scientific research documents, whether they are published or not. The documents may come from teaching and research institutions in France or abroad, or from public or private research centers.
L'archive ouverte pluridisciplinaire HAL, est destinée au dépôt et à la diffusion de documents scientifiques de niveau recherche, publiés ou non, émanant des établissements d'enseignement et de recherche français ou étrangers, des laboratoires publics ou privés. 


\section{Body-size shifts in aquatic and terrestrial urban communities}

Thomas Merckx ${ }^{1}$, Caroline Souffreau ${ }^{2}$, Aurélien Kaiser ${ }^{1}$, Lisa F. Baardsen ${ }^{3}$, Thierry Backeljau ${ }^{3,4}$, Dries Bonte ${ }^{5}$, Kristien I. Brans ${ }^{2}$, Marie Cours ${ }^{6}$, Maxime Dahirel ${ }^{5,7}$, Nicolas Debortoli ${ }^{8}$, Katrien De Wolf ${ }^{4}$, Jessie M. T.

Engelen $^{2}$, Diego Fontaneto ${ }^{9}$, Andros T. Gianuca ${ }^{2,10,11}$, Lynn Govaert ${ }^{2}$, Frederik Hendrickx ${ }^{4,5}$, Janet Higuti ${ }^{12}$, Luc Lens $^{5}$, Koen Martens ${ }^{6,13}$, Hans Matheve ${ }^{5}$, Erik Matthysen ${ }^{3}$, Elena Piano ${ }^{4,14}$, Rose Sablon ${ }^{4}$, Isa Schön ${ }^{6,15}$, Karine Van Doninck ${ }^{8}$, Luc De Meester ${ }^{2,16}$ \& Hans Van Dyck ${ }^{1,16}$

${ }^{1}$ Behavioural Ecology and Conservation Group, Biodiversity Research Centre, Earth and Life Institute, Université catholique de Louvain, Louvain-La-Neuve, Belgium.

${ }^{2}$ Laboratory of Aquatic Ecology, Evolution and Conservation, KU Leuven, Leuven, Belgium.

${ }^{3}$ Evolutionary Ecology Group, University of Antwerp, Antwerp, Belgium.

${ }^{4}$ Directorate Taxonomy and Phylogeny, Royal Belgian Institute of Natural Sciences, Brussels, Belgium.

${ }^{5}$ Terrestrial Ecology Unit, Biology Department, Ghent University, Ghent, Belgium.

${ }^{6}$ Directorate Natural Environment, Royal Belgian Institute of Natural Sciences, Brussels, Belgium.

${ }^{7}$ ECOBIO (Ecosystèmes, biodiversité, évolution), CNRS, Univ Rennes, Rennes, France.

${ }^{8}$ Laboratory of Evolutionary Genetics and Ecology, URBE, NAXYS, University of Namur, Namur, Belgium.

${ }^{9}$ National Research Council, Institute of Ecosystem Study, Verbania-Pallanza, Italy.

${ }^{10}$ German Centre for Integrative Biodiversity Research (iDiv), Halle-Jena-Leipzig, Germany.

${ }^{11}$ Helmholtz Centre for Environmental Research (UFZ), Department of Community Ecology, Halle, Germany.

${ }^{12}$ Centre of Research in Limnology, Ichthyology and Aquaculture/PEA, State University of Maringá, Maringá, Brazil.

${ }^{13}$ Limnology Research Unit, Biology Department, Ghent University, Ghent, Belgium.

${ }^{14}$ Department of Life Sciences and Systems Biology, University of Turin, Turin, Italy.

${ }^{15}$ Zoology Research Group, University of Hasselt, Hasselt, Belgium.

${ }^{16}$ These authors jointly supervised this work: Luc De Meester, Hans Van Dyck 
Body size is intrinsically linked to metabolic rate and life-history traits, and is a crucial determinant of food webs and community dynamics ${ }^{1,2}$. The increased temperatures associated with the urban-heat-island effect result in increased metabolic costs and are expected to drive shifts to smaller body sizes $^{3}$. Urban environments are, however, also characterized by substantial habitat fragmentation ${ }^{4}$, which favours mobile species. Here, using a replicated, spatially nested sampling design across ten animal taxonomic groups, we show that urban communities generally consist of smaller species. In addition, although we show urban warming for three habitat types and associated reduced community-weighted mean body sizes for four taxa, three taxa display a shift to larger species along the urbanization gradients. Our results show that the general trend towards smaller-sized species is overruled by filtering for larger species when there is positive covariation between size and dispersal, a process that can mitigate the low connectivity of ecological resources in urban settings ${ }^{5}$. We thus demonstrate that the urban-heat-island effect and urban habitat fragmentation are associated with contrasting community-level shifts in body size that critically depend on the association between body size and dispersal. Because body size determines the structure and dynamics of ecological networks ${ }^{1}$, such shifts may affect urban ecosystem function.

Body size is a fundamental species trait relating to space use and key life-history features such as longevity and fecundity ${ }^{6}$. It also drives interspecific relationships, thus affecting ecological network dynamics ${ }^{1}$. Size-biased species loss has profound effects on ecosystem function ${ }^{7,8}$. Ectotherms rely on ambient conditions to achieve operational body temperatures ${ }^{9}$. Because higher ambient temperature increases metabolic rates and the associated costs for a given body $\operatorname{size}^{2}$, global climatic warming is expected to drive shifts to communities consisting of smaller species ${ }^{3}$.

Our planet is urbanizing quickly ${ }^{10}$, which is a primary example of human-induced rapid environmental change. Cities are urban heat islands characterized by increased temperatures that are decades ahead of global averages ${ }^{11}$. Not only are cities warmer than surrounding areas, but they also experience extensive fragmentation of (semi-)natural habitats, and both of these effects increase with percentage built-up cover (BUC; a proxy for

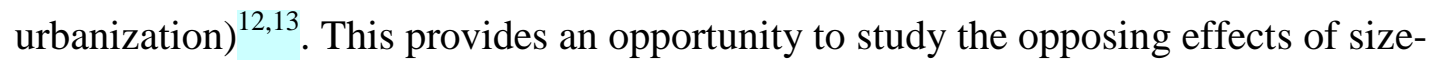
dependent thermal tolerance and dispersal capacity, as larger body size favours dispersal in some, but not all, taxa. 
Here we test the hypothesis that urbanization causes shifts in community-level body size, and that these shifts are dictated by the community-specific association between body size and dispersal. We generally expect the urban-heat-island effect to drive shifts to species with smaller body sizes in communities of ectothermic species, in line with Atkinson's temperature-size rule ${ }^{14}$. For taxa characterized by a positive association between body size and dispersal, however, we also expect a filtering in favour of larger-bodied species associated with habitat fragmentation ${ }^{5,15}$. Filtering for increased mobility has been demonstrated for urban ground beetle and plant communities ${ }^{16,17}$. Hence, for taxa characterized by a positive body-size-dispersal link, we predict that the general communitylevel pattern of smaller species with increasing urbanization may be neutralized or even reversed.

To test our hypothesis, we engaged in an analysis of community-level shifts in body size across a broad range of both terrestrial and aquatic taxa along the same systematically sampled urbanization gradients. We studied the direction of change of community-level body size in ten taxa using a replicated, highly standardized and nested sampling design that covers urbanization gradients at seven spatial scales (50-3,200 m radii; Fig. 1). We sampled each taxon at up to 81 sites, sampling 95,001 individuals from 702 species, with species-specific body size varying by a factor of 400 (0.2-80 mm; Extended Data Table 1$)$. Three of the ten groups are characterized by a positive association between body size and dispersal capacity (see Extended Data Table 1).

We show that the local temperature of pond, grassland and woodland habitats significantly increases with urbanization (linear mixed regression models, $P<0.002$; Extended Data Table 2). The intensity of these urban-heat-island effects is consistently larger during night and summer, in accordance with slower night-time city cooling and higher irradiation levels in summer ${ }^{18}$ (Fig. 2, Extended Data Fig. 1, Extended Data Table 2). We also show that increased urbanization is linked to significant declines in habitat amount and the patch size of terrestrial habitats, and significant increases in distances among patches for both terrestrial and aquatic habitats (Pearson's $r$ correlations, $P \leq 0.020$; Extended Data Fig. 2).

Confirming our metabolism-based prediction that interspecific mean body size decreases with increasing temperature, urban communities for four out of the seven taxa (ground spiders, ground beetles, weevils and cladocerans) that did not have a positive sizedispersal link display reduced community-weighted mean body size (CWMBS). For ostracods, bdelloid rotifers and web spiders, no relationship with urbanization is found. By 
contrast, all three taxa with positive size-dispersal links display increased CWMBS in response to urbanization (Figs. 3, 4, Extended Data Table 3). The positive shifts in size observed for these taxa are in line with our prediction that increased urbanization-mediated habitat fragmentation selects for larger species in taxa with positive size-dispersal links.

The Benjamini-Hochberg procedure ${ }^{19}$, which controls for false positives, confirms that all seven responses are significant at the study-wide level. Comparing the percentage changes in body size over a percentage BUC gradient of 0-25\% shows a marked difference between taxa with a positive size-dispersal link (13.6\% $\pm 8.3 \%$ (mean \pm s.e.m.) body size increase) versus the other taxa $(15.6 \% \pm 5.3 \%$ body size decrease) (weighted two-sided analysis of variance (ANOVA): $F_{1,8}=12.38 ; P=0.0079$ ). These community-level shifts in body size occur independently of shifts in species abundance and diversity along the urbanization gradients. For example, reduced diversity is apparent for taxa that display positive and negative size shifts, as well as for web spiders that lack a size shift. By contrast, cladocerans show size reduction without diversity change (Extended Data Table 4). For butterflies, macro-moths and orthopterans (that is, taxa with a positive size-dispersal link), the increase in the CWMBS ranges from $7 \%$ to $21 \%$ depending on the taxon, whereas size reductions of ground beetles, weevils and ground spiders (that is, terrestrial taxa with nonpositive size-dispersal links) range from $-18 \%$ to $-21 \%$ over an urbanization gradient of 0 $25 \%$ BUC (Fig. 3). The cladocerans display the largest size reduction (-44\%), in accordance with the temperature-size response generally being stronger in aquatic species than in terrestrial species as a result of the greater oxygen limitation in water ${ }^{20}$. However, the size reduction for the ostracods is much smaller (-13\%) and non-significant (linear mixed regression model, $P=0.10$ ), and for the rotifers no size shift is found. The absence of a size shift for the microscopic rotifers might indicate that their small size allows for sufficient oxygen exchange between warm, low-oxygen environments and body tissues, so that no community shift to smaller body sizes is induced by increased temperature. The absence of a size shift for web spiders may be explained by behavioural flexibility in their extended phenotype, as modified web designs help web-spider communities to adapt to urbanizationinduced lower average body size of aerial dipteran prey $^{21}$.

Our multi-scale approach allows the pinpointing of the spatial scales at which urbanization best explains the observed effects. During winter, the urban-heat-island effect fades with increasing spatial scale during the day but not at night, whereas during summer both diurnal and nocturnal urban-heat-island effects are more pronounced at small scales (Fig. 
2, Extended Data Fig. 1, Extended Data Table 2). The spatial scale at which most of the variation in CWMBS is explained varied considerably among taxa, with effects for smallersized taxa prevailing at small spatial scales (Figs. 3, 4, Extended Data Table 3).

Urbanization induces biodiversity loss and biotic homogenization ${ }^{10}$ (see also Extended Data Table 4). Here, we demonstrate that urbanization also leads to community-wide shifts in body size for the majority of studied species groups. The size reductions within aquatic and terrestrial taxa follow metabolic rules in line with the urban-heat-island effect, especially as our data on various pollutants suggest no correlation with percentage BUC (data not shown). By contrast, the increased fragmentation that is a result of urbanization appears to cause size increases for taxa with positive size-dispersal links. Hence, our multi-taxa study provides evidence of bi-directional shifts in community body size. In addition to the interspecific patterns reported here, shifts in body size can also occur at the intraspecific level, through phenotypic plasticity and genotypic change ${ }^{22-24}$. Our results should enable mechanistic studies that elucidate the cause of the variation in the observed shifts in body size along urban gradients and quantify their functional effects in urban ecosystems. A better insight into the mechanisms behind shifts in body size will allow prediction of the intertwined effects of climate change and urbanization on the body-size distribution of communities.

The size-biased species loss reported here is expected to strongly affect ecosystem function $^{7,8}$. If taxa in urban areas are represented by smaller or larger species, ecosystem structure and function will be affected in several ways. Metabolic theory and a recent artificial-selection experiment predict that shifted size distributions affect whole-ecosystem properties such as primary productivity, carbon cycling and decomposition ${ }^{25,26}$. Shifts in body size also translate into altered life histories, demographic rates and interspecific relationships ${ }^{1,2}$. For example, consumer-resource dynamics have recently been modelled for warming-related intraspecific size shifts mediated by phenotypic plasticity ${ }^{27}$. A clear-cut effect of shifts in body size on ecosystem function can be predicted for cladoceran zooplankton. Smaller-sized cladoceran communities are typified by reduced densities of large Daphnia species (highly efficient filter feeders that consume phytoplankton), and are thus less able to maintain top-down control on algal blooms than larger-sized communities ${ }^{28}$. Also, the observed shifts in macro-moth body-size distributions may be functionally linked to flowering plant diversity through pollination ${ }^{29,30}$.

The shifts in body size that we observe across a range of animal taxa will be directly relevant to future efforts to understand, predict and mediate population resilience, trophic 
interactions, and ecosystem function in urban ecosystems ${ }^{31,32}$. Such insights will be essential to design the biodiverse towns and cities of the future. For example, urban planners could mitigate the micro-climatic effects and habitat fragmentation that result from urbanization with measures implemented at multiple spatial scales. Such interventions could involve the creation and/or modification of urban ponds and urban green infrastructure to increase the amount and quality of habitats ${ }^{33}$. Doing so would reduce the urban-heat-island effect and favour dispersal, and hence gene flow, in urban animal populations. Our results indicate that such impacts would maintain variation in the body-size distributions of urban communities and potentially mitigate the effect that shifts in body size may have on ecosystem function.

Online content Any Methods, including any statements of data availability and Nature Research reporting summaries, along with any additional references and Source Data files, are available in the online version of the paper at https://XXX

Received 11 July 2017; accepted 11 April 2018

$<$ jrn $>1$. Woodward, G. et al. Body size in ecological networks. Trends Ecol. Evol. 20, 402409 (2005). </jrn>

$<$ jrn>2. Brown, J. H., Gillooly, J. F., Allen, A. P., Savage, V. M. \& West, G. B. Toward a metabolic theory of ecology. Ecology 85, 1771-1789 (2004). </jrn>

$<$ jrn $>3$. Scheffers, B. R. et al. The broad footprint of climate change from genes to biomes to people. Science 354, aaf7671 (2016). </jrn>

<jrn>4. Alberti, M., Marzluff, J. \& Hunt, V. M. Urban driven phenotypic changes: empirical observations and theoretical implications for eco-evolutionary feedback. Phil. Trans. R. Soc. Lond. B 372, 20160029 (2017). </jrn>

$<$ jrn>5. Cheptou, P. O., Hargreaves, A. L., Bonte, D. \& Jacquemyn, H. Adaptation to fragmentation: evolutionary dynamics driven by human influences. Phil. Trans. $R$. Soc. Lond. B 372, 20160037 (2017). </jrn>

$<$ jrn>6. Chown, S. L. \& Gaston, K. J. Body size variation in insects: a macroecological perspective. Biol. Rev. Camb. Philos. Soc. 85, 139-169 (2010). </jrn>

$<$ jrn>7. Kalinkat, G. et al. Body masses, functional responses and predator-prey stability. Ecol. Lett. 16, 1126-1134 (2013). </jrn>

$<\mathrm{jrn}>8$. Brose, U. et al. Predicting the consequences of species loss using size-structured biodiversity approaches. Biol. Rev. Camb. Philos. Soc. 92, 684-697 (2017). </jrn> 
$<$ jrn>9. Horne, C. R., Hirst, A. G. \& Atkinson, D. Seasonal body size reductions with warming covary with major body size gradients in arthropod species. Proc. Biol. Sci. 284, 20170238 (2017). </jrn>

$<$ jrn>10. Seto, K. C., Güneralp, B. \& Hutyra, L. R. Global forecasts of urban expansion to 2030 and direct impacts on biodiversity and carbon pools. Proc. Natl Acad. Sci. USA 109, 16083-16088 (2012). </jrn>

<jrn>11. Youngsteadt, E., Dale, A. G., Terando, A. J., Dunn, R. R. \& Frank, S. D. Do cities simulate climate change? A comparison of herbivore response to urban and global warming. Glob. Chang. Biol. 21, 97-105 (2015). </jrn>

$<$ jrn>12. Ward, K., Lauf, S., Kleinschmit, B. \& Endlicher, W. Heat waves and urban heat islands in Europe: a review of relevant drivers. Sci. Total Environ. 569-570, 527-539 (2016). </jrn>

$<$ bok>13. Niemelä. J. Urban Ecology: Patterns, Processes, and Applications (Oxford Univ. Press, Oxford, 2011). $<$ /bok $>$

$<\mathrm{jrn}>14$. Atkinson, D. Temperature and organism size: a biological law for ectotherms? Adv. Ecol. Res 25, 1-58 (1994). </jrn>

$<$ jrn $>$ 15. Bonte, D. \& Dahirel, M. Dispersal: a central and independent trait in life history. Oikos 126, 472-479 (2017). </jrn>

$<$ jrn $>$ 16. Piano, E. et al. Urbanization drives community shifts towards thermophilic and dispersive species at local and landscape scales. Glob. Chang. Biol. 23, 2554-2564 (2017). </jrn>

<jrn>17. Concepción, E. D., Moretti, M., Altermatt, F., Nobis, M. P. \& Obrist, M. K. Impacts of urbanisation on biodiversity: the role of species mobility, degree of specialisation and spatial scale. Oikos 124, 1571-1582 (2015). </jrn>

$<$ jrn $>$ 18. Arnfield, A. J. Two decades of urban climate research: a review of turbulence, exchanges of energy and water, and the urban heat island. Int. J. Climatol. 23, 1-26 (2003). </jrn>

$<$ jrn>19. Benjamini, Y. \& Hochberg, Y. Controlling the false discovery rate: a practical and powerful approach to multiple testing. J. R. Stat. Soc. B Stat. Methodol. 57, 289300 (1995). $<$ /jrn> 
$<$ jrn $>20$. Forster, J., Hirst, A. G. \& Atkinson, D. Warming-induced reductions in body size are greater in aquatic than terrestrial species. Proc. Natl Acad. Sci. USA 109, 19310-19314 (2012). </jrn>

$<$ jrn>21. Dahirel, M., Dierick, J., De Cock, M. \& Bonte, D. Intraspecific variation shapes community-level behavioral responses to urbanization in spiders. Ecology $\mathbf{9 8}$, 2379-2390 (2017). </jrn>

$<$ jrn $>22$. McDonnell, M. J. \& Hahs, A. K. Adaptation and adaptedness of organisms to urban environments. Annu. Rev. Ecol. Evol. Syst. 46, 261-280 (2015). </jrn>

$<$ jrn $>23$. Alberti, M. et al. Global urban signatures of phenotypic change in animal and plant populations. Proc. Natl Acad. Sci. USA 114, 8951-8956 (2017). </jrn>

$<$ unknown>24. Johnson, M. T. J. \& Munshi-South, J. Evolution of life in urban environments. Science 358, eaam8327 (2017). </unknown>

<jrn>25. Schramski, J. R., Dell, A. I., Grady, J. M., Sibly, R. M. \& Brown, J. H. Metabolic theory predicts whole-ecosystem properties. Proc. Natl Acad. Sci. USA 112, 2617-2622 (2015). </jrn>

<jrn>26. Malerba, M. E., White, C. R. \& Marshall, D. J. Eco-energetic consequences of evolutionary shifts in body size. Ecol. Lett. 21, 54-62 (2018). </jrn>

$<\mathrm{jrn}>27$. Osmond, M. M. et al. Warming-induced changes to body size stabilize consumer-resource dynamics. Am. Nat. 189, 718-725 (2017). </jrn>

$<$ jrn>28. Gianuca, A. T., Pantel, J. H. \& De Meester, L. Disentangling the effect of body size and phylogenetic distances on zooplankton top-down control of algae. Proc. Biol. Sci. 283, 20160487 (2016). </jrn>

<jrn>29. Agosta, S. J. \& Janzen, D. H. Body size distributions of large Costa Rican dry forest moths and the underlying relationship between plant and pollinator morphology. Oikos 108, 183-193 (2005). </jrn>

$<$ jrn $>$ 30. Biesmeijer, J. C. et al. Parallel declines in pollinators and insect-pollinated plants in Britain and the Netherlands. Science 313, 351-354 (2006). </jrn>

$<$ jrn $>$ 31. Duffy, J. E. Biodiversity loss, trophic skew and ecosystem functioning. Ecol. Lett. 6, 680-687 (2003). </jrn> 
<jrn>32. Webb, C. T., Hoeting, J. A., Ames, G. M., Pyne, M. I. \& LeRoy Poff, N. A structured and dynamic framework to advance traits-based theory and prediction in ecology. Ecol. Lett. 13, 267-283 (2010). </jrn>

$<$ jrn>33. Threlfall, C. G. et al. Increasing biodiversity in urban green spaces through simple vegetation interventions. J. Appl. Ecol. 54, 1874-1883 (2017). </jrn>

Acknowledgements We thank M. De Cock, J. Dierick, P. Limbourg, E. van den Berg, M. Van Kerckvoorde and P. Vantieghem for help with sampling and identification of species. This is publication BRC419 of the Biodiversity Research Centre (UCL/ELI). This research is part of the SPEEDY-project, funded by the Interuniversity Attraction Poles program of the Belgian Science Policy Office BELSPO (IAP-grant P7/04).

Reviewer information Nature thanks M. McDonnell and the other anonymous reviewer(s) for their contribution to the peer review of this work.

Author contributions T.M., L.D.M. and H.V.D. conceived the study. C.S. and L.D.M. coordinated the consortium. T.M., C.S., A.K., L.F.B., T.B., D.B., K.I.B., M.C., M.D., N.D., K.D.W., J.M.T.E., D.F., A.T.G., L.G., F.H., J.H., L.L., K.M., E.M., E.P., R.S. and I.S. contributed to sampling and data collection. T.M. and A.K. performed the analyses. H.M. selected study plots, calculated fragmentation variables and designed the study area map. T.M. wrote the first draft of the manuscript with all authors contributing substantially to revisions.

Competing interests: The authors declare no competing interests.

\section{Additional information}

Extended data is available for this paper at

Reprints and permissions information is available at www.nature.com/reprints.

Correspondence and requests for materials should be addressed to T.M.

Publisher's note: Springer Nature remains neutral with regard to jurisdictional claims in published maps and institutional affiliations. 
Fig. 1 Map of the study area. The configuration of 27 landscape-scale sampling plots (nine urban, magenta; nine semi-urban, yellow; nine non-urban, green) on an urbanization background (light and dark corresponds to non-urban and urban gradient, respectively). Solid lines refer to administrative province borders. Three plots are enlarged, showing the distribution of local subplot types within each plot. Subplots allowed sampling using a nested design that covers urbanization gradients at both the landscape and local scale. Different sets of subplots were selected among taxa, so that subplots always contained the corresponding habitats. Urbanization was quantified as the percentage BUC (assessed using a reference map with building contours; LRD, https://www.agiv.be/international/en/products/grb-en) for each sample site at seven spatial scales (50-3,200 m radii, depicted as black circles around one of the three sample sites of one non-urban plot). Photographs depict sites in a non-urban and urban subplot, for both aquatic (top row) and terrestrial (bottom row) systems. Corine Land Cover map for northern Belgium, copyright NGI (2017); map of western Europe, Ocean Basemap, copyright Esri.

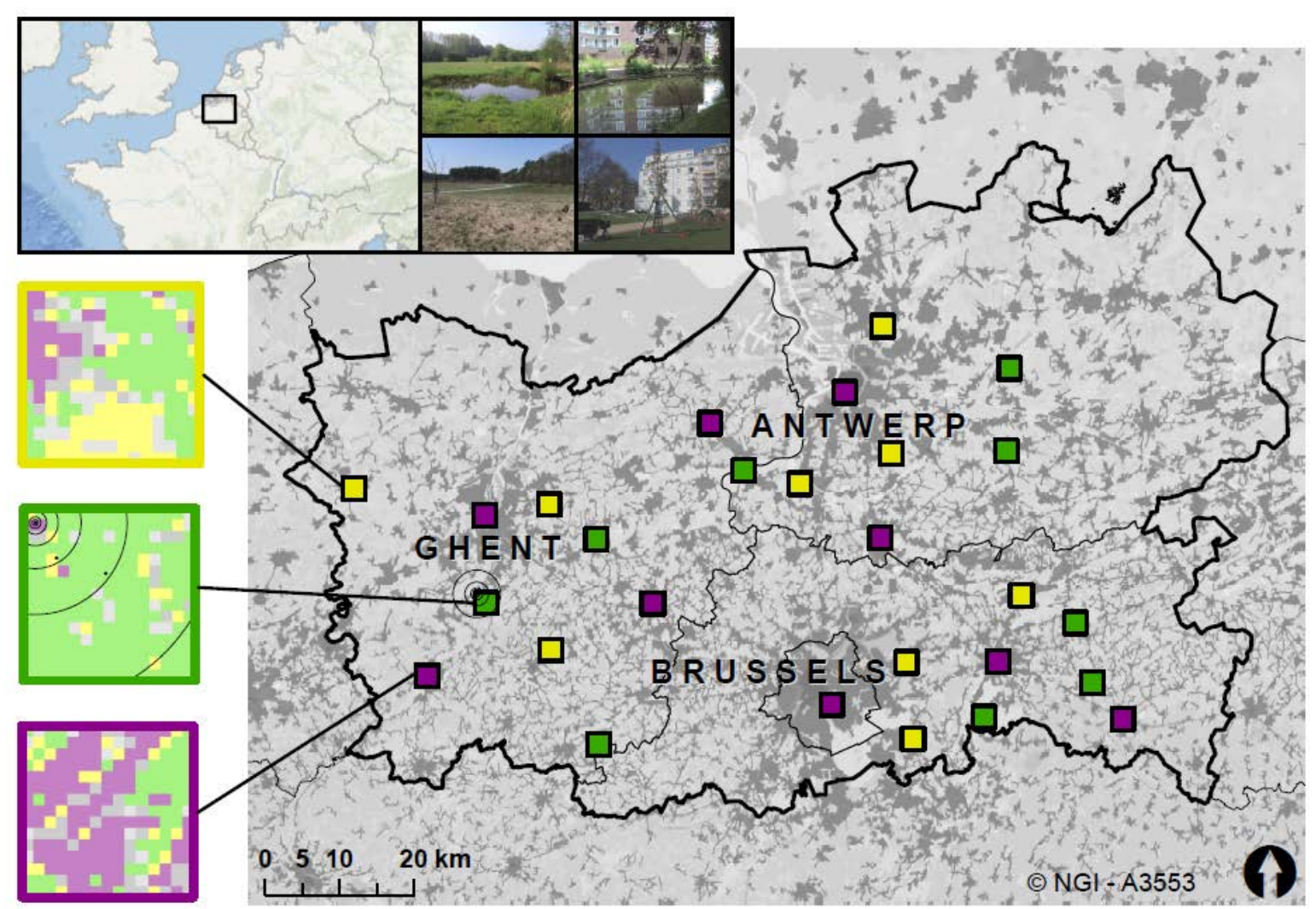


Fig. 2 | Micro-climatic urban-heat-island effects. a-d, Mean temperature increase $\left({ }^{\circ} \mathrm{C}\right)$ when comparing sites that differed by 25\% BUC. Effects for pond, grassland and woodland habitats are merged, and displayed separately for seven spatial scales (50-3,200 m radii at which urbanization was quantified). a, Summer diurnal ( $n=103$ sites). b, Winter diurnal ( $n=93$ sites). c, Summer nocturnal ( $n=103$ sites). d, Winter nocturnal ( $n=93$ sites). Temperature averages were analysed in relation to site-specific percentage BUC values using linear mixed regression models. We calculated mean changes in temperature over a $0-25 \%$ BUC gradient, on the basis of model-estimated intercepts and slopes. Error bars represent the range of temperature change on the basis of these slopes with 95\% confidence intervals.
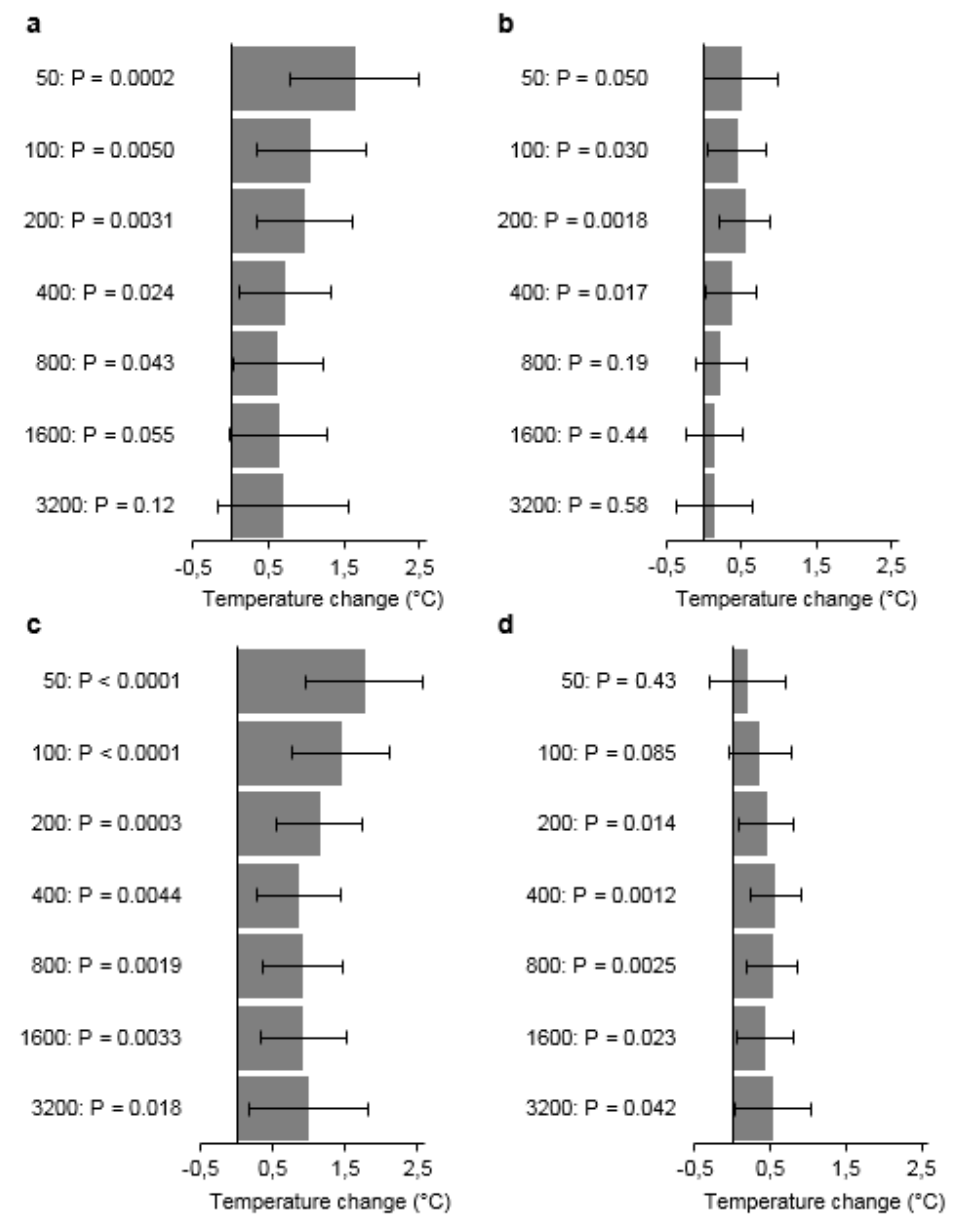


\section{Fig. 3 | Taxon-specific percentage change in CWMBS for a 0-25\% change in}

urbanization. Modelled extent of the mean percentage change in CWMBS for each taxon when comparing sites that differed by 25\% BUC. CWMBS was analysed for each taxon ( $n=76,12,75,80,62,60,81,81,68$ and 80 biologically independent communities from top to bottom) in relation to site-specific percentage BUC values using linear mixed regression models. We calculated the percentage change in CWMBS over a 0-25\% BUC gradient for each taxon, at the spatial scale of the best-fitting model, on basis of the modelled intercept and slope. Error bars are based on the 95\% confidence intervals of the regression slopes. No adjustments were made for multiple comparisons, but the Benjamini-Hochberg procedure ${ }^{19}$ confirmed that all significant responses were truly significant. Numbers indicate the scale (metres radius) of the best-fitting model, the range given between brackets indicates the radii of the models which are within the confidence set. Dark grey bars correspond to taxa with a positive size-dispersal link. Animal silhouettes from PhyloPic (http://www.phylopic.org) fall under CC-BY 3.0 licences; credits (top to bottom): M. Broussard, G. Monger, D. Fontaneto et al., G. Monger, B. Lang, M. Dahirel, S. Harmer et al., T. Assmann et al., E. Schmidt \& M. Dahirel, public domain.

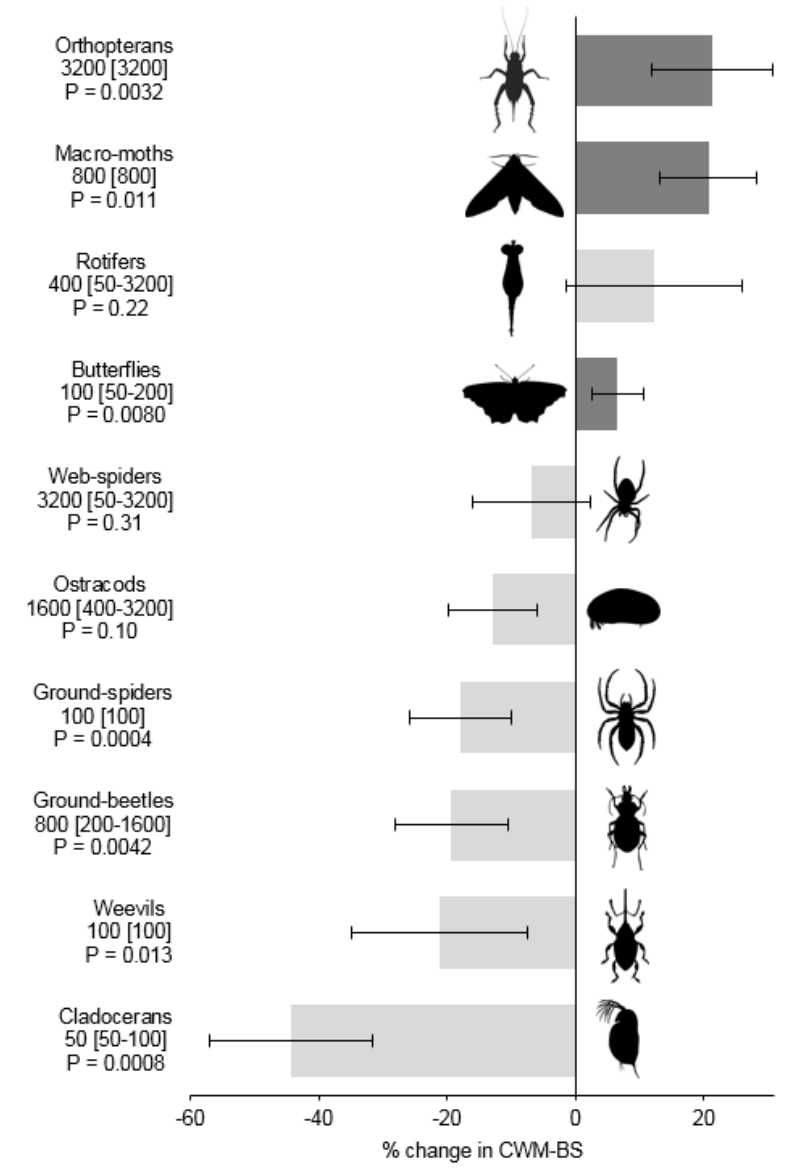


Fig. 4 | Taxon-specific plots of CWMBS as a function of urbanization. a-j, Modelled CWMBS (mm) values of all taxa plotted against percentage BUC at the spatial scale (metres radius) of the best-fitting model. a, Orthopterans (spatial scale of best-fitting model: 3,200 m). b, Macro-moths (800 m). c, Rotifers (400 m). d, Butterflies (100 m). e, Web spiders (3,200 m). f, Ostracods (1,600 m). g, Ground spiders (100 m). h, Ground beetles (800 m). i, Weevils (100 m). j, Cladocerans (50 m). $n=76,12,75,80,62,60,81,81,68$ and 80 biologically independent communities for $\mathbf{a}-\mathbf{j}$, respectively. CWMBS values are logtransformed for ostracods and cladocerans (depicted range: 0.55-1.66 and 0.26-1.89 mm, respectively), and for the former, the percentage BUC values are also transformed (depicted range, 1.5-47.8\%). Modelled linear regression slopes with 95\% confidence intervals (shaded regions) are shown. Image credits as in Fig. 3.
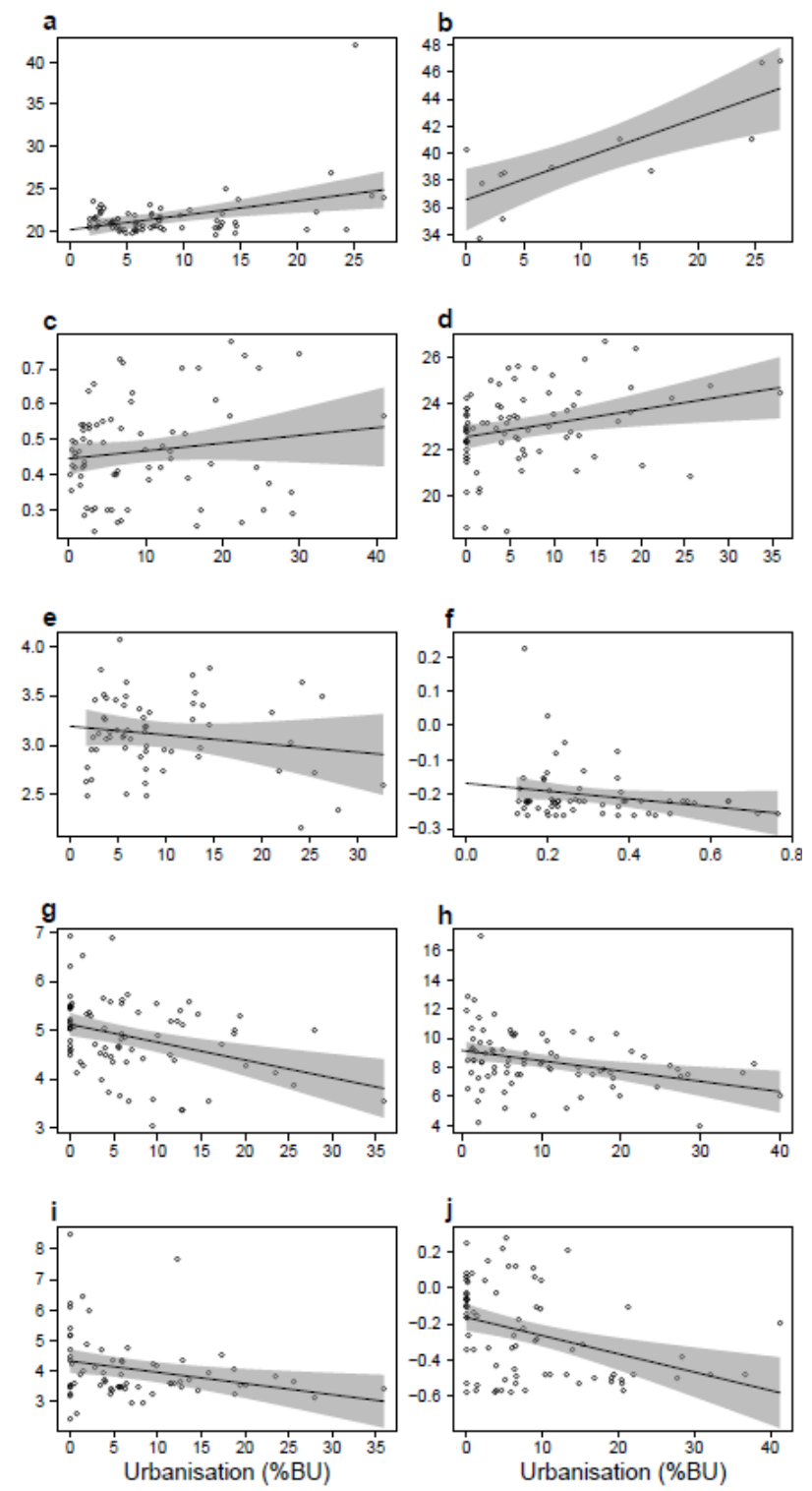


\section{METHODS}

\section{Sampling design}

Sampling was performed according to a nested design in which a local urbanization gradient (three classes: non-urban, semi-urban and urban) was repeatedly sampled within landscapes distributed along a landscape-scale urbanization gradient (three classes: non-urban, semiurban and urban). For each of ten taxa a total of up to 81 local-scale subplots $(200 \times 200 \mathrm{~m})$ were sampled within 27 landscape-scale plots $(3 \times 3 \mathrm{~km})$ situated in an 8,140 $\mathrm{km}^{2}$ study area in northern Belgium (Fig. 1, Extended Data Table 1). The average human population density of this highly urbanized area amounts to 693 individuals per $\mathrm{km}^{2}$, with cities and urban sprawl embedded within an agricultural and semi-natural matrix ${ }^{34}$. As a proxy for urbanization we used percentage BUC, which was assessed in a geographic information system (GIS) using an object-oriented reference map of Flanders with the precise contours of all buildings, excluding roads and parking infrastructures, as a vectorial layer. Given that only buildings are considered, 15\% BUC can be considered highly urbanized. Within each of the nine urban (BUC > 15\%), nine semi-urban (5\% < BUC < 10\%) and nine non-urban (BUC < 3\%) plots, one urban, one semi-urban and one non-urban subplot were chosen using identical BUC cutoff values, for a total of 81 subplots. Within each subplot, and for each of the ten taxa, a single grassland, woodland or pond habitat patch was targeted for sampling during the most appropriate season for each taxon (Extended Data Table 1). As each taxon was sampled in only one of three habitat types (that is, grassland, woodland or ponds), it was often impossible to sample all taxa within the same $200 \times 200$ m subplots. As such, independent subplots containing the corresponding habitats were sometimes selected among taxa, but these subplots were always of the same urbanization level and located within the same $3 \times 3 \mathrm{~km}$ plot.

The classification of urban, semi-urban and non-urban (sub)plots on the basis of BUC cut-off values was used to establish the nested sampling design, which allowed samples to display a wide range of urbanization values at both local (subplot) and landscape (plot) scales. To increase precision in the data analysis, however, we moved away from having BUC as a class variable with three levels, and instead quantified BUC as a continuous variable, at seven spatial scales around the sampling site (50, 100, 200, 400, 800, 1,600 and 3,200 m radii). Owing to our nested design, BUC values at small scales were not correlated with values at large scales, hence allowing the pinpointing of the scales at which the effects of urbanization are most pronounced. 
Using this highly replicated, nested sampling design, our sampling effort involved counting and assigning 95,001 individuals to 702 species in ten taxa: (i) aquatic: cladocerans and ostracods sampled in pond habitats; (ii) limno-terrestrial: aquatic bdelloid rotifers sampled within the water layers of terrestrial Xanthoria lichens; and (iii) terrestrial: butterflies, orthopterans (that is, grasshoppers and bush crickets), macro-moths, ground beetles, weevils, web spiders and ground spiders sampled in grassland and woodland habitats (Extended Data Table 1).

\section{Urban-heat-island effect}

The urban-heat-island effect was quantified using hourly temperature readings that were collected automatically across 104 sampling sites for the three habitat types in which the ten taxa were sampled: ponds, grasslands and woodlands. Aquatic probes (HOBO, TidbiT v2 UTBI-001; HOBOware ONSET; resolution: $0.02{ }^{\circ} \mathrm{C}$ ) were attached to a floating device to log temperatures at $15 \mathrm{~cm}$ depth for 18 ponds (27 November 2014-29 November 2015). Terrestrial probes (iButton, Thermochron DS1923, Maxim Integrated; resolution: $0.06{ }^{\circ} \mathrm{C}$ ) logged air temperature at $20 \mathrm{~cm}$ height near 59 pitfall sites (that is, grassland habitat; 8 May 2014-20 September 2015; 59 and 49 sites during summer and winter, respectively) and 27 macro-moth sampling sites (that is, woodland habitat; 1 April 2015-20 March 2016; 26 sites each during summer and winter). For each day, temperature averages of twelve diurnal (07:00-18:00) and twelve nocturnal (19:00-06:00) readings were calculated, which were labelled as summer from 21 March-20 September, and as winter from 21 September-20 March.

\section{Habitat fragmentation}

Correlations between urbanization (BUC) and three habitat fragmentation variables (that is, habitat coverage, mean size of habitat patches, and mean nearest-neighbour distance among habitat patches) were quantified using Pearson's $r$ coefficients (Extended Data Fig. 2). This was done at a $3 \times 3 \mathrm{~km}$ plot scale, on the basis of detailed land-use data from all 27 sampling plots (Fig. 1), and separately for terrestrial (that is, all types of (semi-)natural habitat) and aquatic habitat (that is, all pond types) ${ }^{35,36}$. Eutrophied, mono-specific intensive grasslands as well as orchards, plantations and conifer woodlands were not retained for analyses.

\section{Statistical analyses}

Temperature averages were analysed in relation to site-specific urbanization (BUC) values and habitat type (grassland, woodland and pond) using linear mixed regression models ( $\mathrm{R}$ 
package lme4). We ran separate models for both seasons (summer and winter) and for both day and night conditions (diurnal and nocturnal). Site ID and date (nested within year) were included as random factors. We used a multi-scale approach, running separate models with BUC values quantified at seven spatial scales (50-3,200 m radii). $P$ values for the fixed effects were obtained using likelihood-ratio tests of nested models that were fitted with maximum-likelihood and parameter estimates from restricted maximum-likelihood models. Residual plots were always visually inspected to evaluate the fit of models, and we compared maximum-likelihood-based AICc values (R package AICcmodavg) to select a confidence set of models whose AICc values did not differ substantially from the value of the best-fitting model, using $\triangle \mathrm{AICc} \leq 2$ as a criterion ${ }^{37}$.

CWMBS was calculated for a given site as the average of the species-specific body sizes (mm) for all locally sampled species, weighted by species abundance. The raw data for calculating this metric are species-level count data for all taxa in all sites (based on taxonspecific sampling and identification protocols) and mean species-specific body-size values extracted from the literature or, in the case of web spiders and cladocerans, from our own measurements (Extended Data Table 1). An increase in CWMBS with increasing urbanization implies that the species assemblage of the site is increasingly composed of individuals belonging to larger species along the gradient from communities in more rural sites to communities in more urban sites. Our CWMBS index hence reflects the relative composition of large versus small species in local communities, and we use it here to quantify community response to urbanization. Although every sampling method introduces some bias in relative species abundances, the extent of the bias should be similar for non-urban and urban sampling sites. Therefore, using the relative species abundances that we obtained via sampling to calculate the CWMBS is appropriate to look into the relative effects of urbanization.

CWMBS was analysed for each taxon in relation to site-specific urbanization (BUC) values using linear mixed regression models with restricted maximum-likelihood estimation (R package lme4). Plot ID was used as a random variable to account for potential spatial autocorrelation of variables among sites belonging to the same landscape-scale plot. CWMBS values were $\log _{10}$-transformed for cladocerans and ostracods. For ostracods, we also transformed BUC values by taking the arcsine of square-rooted BUC values, which resulted in residual plots with a more homogeneous distribution. Analyses for the other taxa were run with untransformed data as residual plots proved to be homogeneous. The residual plots for orthopterans, ostracods and ground beetles each displayed one outlying data point, and the 
residual plot for weevils displayed two such points. Because these five data points are legitimate (that is, they are not due to measurement, data or sampling errors) we assessed their effect on the consistency of the regressions in the model output. Filtering these data points out of the regressions showed (i) that the best-fitting models remained linked to the identical spatial scales; (ii) that the positive slope for orthopterans remained positive and the negative slopes for the other taxa remained negative, and (iii) that the significance levels stayed equal for ground beetles and ostracods, got stronger for weevils, and decreased but remained significant for orthopterans. Because those five data points are legitimate and do not have a qualitative effect on the output, we opted to retain them in the analyses. We used a multi-scale approach, running separate models with BUC values quantified at seven spatial scales (503,200 m radii). For each taxon, we then selected the model (and hence the spatial scale) that fitted the data best using maximum-likelihood-based AICc values (R package AICcmodavg). We also retained a confidence set of the models whose AICc values did not differ substantially from the value of the best model using $\triangle \mathrm{AICc} \leq 2$ as a criterion ${ }^{37}$.

For each taxon, and at the spatial scale of the best-fitting model, we calculated the percentage change (with 95\% confidence interval) in CWMBS over a 0-25\% BUC gradient, on the basis of the modelled intercept and slope, or of back-transformed values for ostracods and cladocerans (Fig. 3). These values were then contrasted for taxa with a positive sizedispersal link against all other taxa using two-sided ANOVA, with the inverse of the taxonspecific error bars as weights to account for the differences among taxa in the variance of the estimated percentage change. This weighted ANOVA allows testing of the percentage change values for taxa with a positive size-dispersal link to determine whether they are significantly different from those of all other taxa.

All statistical analyses were performed using R v.3.2.3 $3^{38}$.

\section{Reporting summary}

Further information on experimental design is available in the Nature Research Reporting Summary linked to this paper.

\section{Data availability}

The datasets generated and analysed during the current study are available from the corresponding author upon reasonable request.

<eref>34. IBZ. Bevolkingscijfers per Provincie en per Gemeente op 1 Januari 2017 http://www.ibz.rrn.fgov.be/fileadmin/user_upload/fr/pop/statistiques/population- 
bevolking-20170101.pdf (Federale Overheidsdienst Binnenlandse Zaken, 2017). $<$ /eref $>$

$<$ bok>35. De Saeger, S. et al. Biologische Waarderingskaart en Natura 2000

Habitatkaart (Instituut voor Natuur en Bosonderzoek, Brussels, 2016). </bok>

$<$ bok>36. Packet, J. et al. Watervlakken Versie 1.0: Polygonenkaart van Stilstaand Water in Vlaanderen. Inhoud en Metadata van een Nieuw Instrument voor Water-, Milieuen Natuurbeleid. (Instituut voor Natuur en Bosonderzoek, Brussels, 2017).</bok>

$<$ bok>37. Burnham, K. P. \& Anderson, D. R. Model Selection and Multimodel Inference: a Practical Information-Theoretic Approach (Springer Science \& Business Media, New York, 2003).</bok>

<bok>38. R Development Core Team. R: A Language and Environment for Statistical Computing; https://www.r-project.org/ (2015).</bok>

$<$ bok>39. Bink, F. A. Ecologische Atlas van de Dagvlinders van Noordwest-Europa (Schuyt \& Co, Haarlem, 1992). $<$ bok $>$

$<$ jrn $>40$. Sekar, S. A meta-analysis of the traits affecting dispersal ability in butterflies: can wingspan be used as a proxy? J. Anim. Ecol. 81, 174-184 (2012). </jrn>

$<$ jrn>41. Stevens, V. M., Trochet, A., Van Dyck, H., Clobert, J. \& Baguette, M. How is dispersal integrated in life histories: a quantitative analysis using butterflies. Ecol. Lett. 15, 74-86 (2012). </jrn>

$<$ jrn $>$ 42. Stevens, V. M. et al. A comparative analysis of dispersal syndromes in terrestrial and semi-terrestrial animals. Ecol. Lett. 17, 1039-1052 (2014). </jrn>

<bok>43. Manley, C. British Moths and Butterflies: a Photographic Guide (A \& C Black, London, 2008). $<$ /bok $>$

$<$ jrn>44. Nieminen, M., Rita, H. \& Uuvana, P. Body size and migration rate in moths. Ecography 22, 697-707 (1999). </jrn>

$<$ jrn $>45$. Slade, E. M. et al. Life-history traits and landscape characteristics predict macro-moth responses to forest fragmentation. Ecology 94, 1519-1530 (2013). </jrn> <jrn>46. Reinhardt, K., Köhler, G., Maas, S. \& Detzel, P. Low dispersal ability and habitat specificity promote extinctions in rare but not in widespread species: the Orthoptera of Germany. Ecography 28, 593-602 (2005). </jrn> 
$<$ bok $>$ 47. Roberts, M. J. The Spiders of Great Britain and Ireland: Compact Edition (Apollo Books, Vester Skerninge, 2009).</bok>

<bok>48. Turin, H. De Nederlandse Loopkevers: Verspreiding en Ecologie (KNNV, Zeist, 2000). $</$ bok $>$

$<$ bok>49. Duff, A. G. et al. Beetles of Britain and Ireland Vol. 4 (A. G. Duff, West Runton, 2016).</bok>

$<$ bok>50. Donner, J. Ordnung Bdelloidea. Bestimmungsbücher zur Bodenfauna Europas (Akademie-Verlag, Berlin, 1965).</bok>

$<$ bok>51. Fontaneto, D. Biogeography of Microscopic Organisms: is Everything Small Everywhere? (Cambridge Univ. Press, Cambridge, 2011).</bok>

$<$ bok>52. Meisch, C. Freshwater Ostracoda of Western and Central Europe (Spektrum Akademischer, Heidelberg, 2000). $<$ /bok $>$

$<$ jrn>53. Bilton, D. T., Freeland, J. R. \& Okamura, B. Dispersal in freshwater invertebrates. Annu. Rev. Ecol. Syst. 32, 159-181 (2001). </jrn>

$<$ jrn $>54$. De Bie, T. et al. Body size and dispersal mode as key traits determining metacommunity structure of aquatic organisms. Ecol. Lett. 15, 740-747 (2012). $<$ jrn $>$

$<$ jrn $>55$. Brans, K. I. et al. Eco-evolutionary dynamics in urbanized landscapes: evolution, species sorting and the change in zooplankton body size along urbanization gradients. Phil. Trans. R. Soc. Lond. B 372, 20160030 (2017). </jrn>

$<$ jrn $>56$. Gianuca, A. T. et al. Taxonomic, functional and phylogenetic metacommunity ecology of cladoceran zooplankton along urbanization gradients. Ecography 41, 183194 (2018). </jrn> 
Extended Data Fig. 1 | Micro-climatic urban-heat-island effect strengths. a, b, Slopes of the urban-heat-island effects (measured as the increase in temperature $\left({ }^{\circ} \mathrm{C}\right.$ ) per $1 \%$ increase in percentage BUC) as a function of spatial scale (the radius at which urbanization was quantified) with 95\% confidence intervals (CI). Separate measurements are shown for summer (red) and winter (blue) using merged readings for pond, grassland and woodland habitats ( $n=104$ sites). a, Diurnal measurements. b, Nocturnal measurements. Data points are offset from one another horizontally to improve clarity.
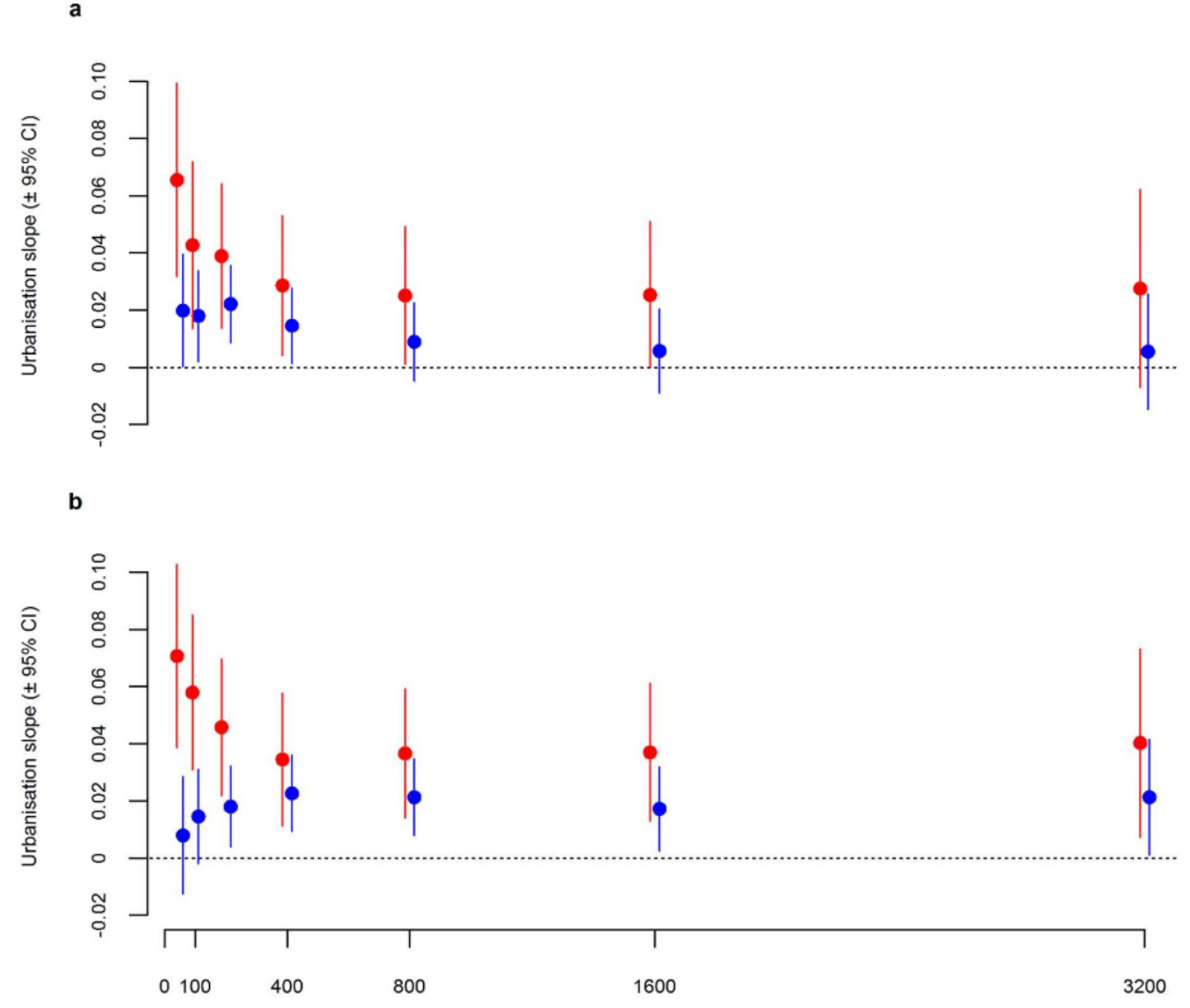


\section{Extended Data Fig. 2 | Correlations between urbanization and habitat fragmentation.}

Correlations between urbanization (measured as the percentage BUC (\%BU)) and three habitat fragmentation variables: habitat coverage (a, b), mean size of habitat patches (c, d), and mean nearest-neighbour distance among habitat patches $(\mathbf{e}, \mathbf{f})$. Separate plots are shown for terrestrial (that is, all types of (semi-)natural habitat, left) and aquatic (that is, all pond types, right) habitats ( $n=27$ landscape-scale sampling plots). Pearson's $r$ coefficients and $P$ values are indicated; not significant (NS), $P>0.1 ; * P<0.05 ; * * * P<0.001$.
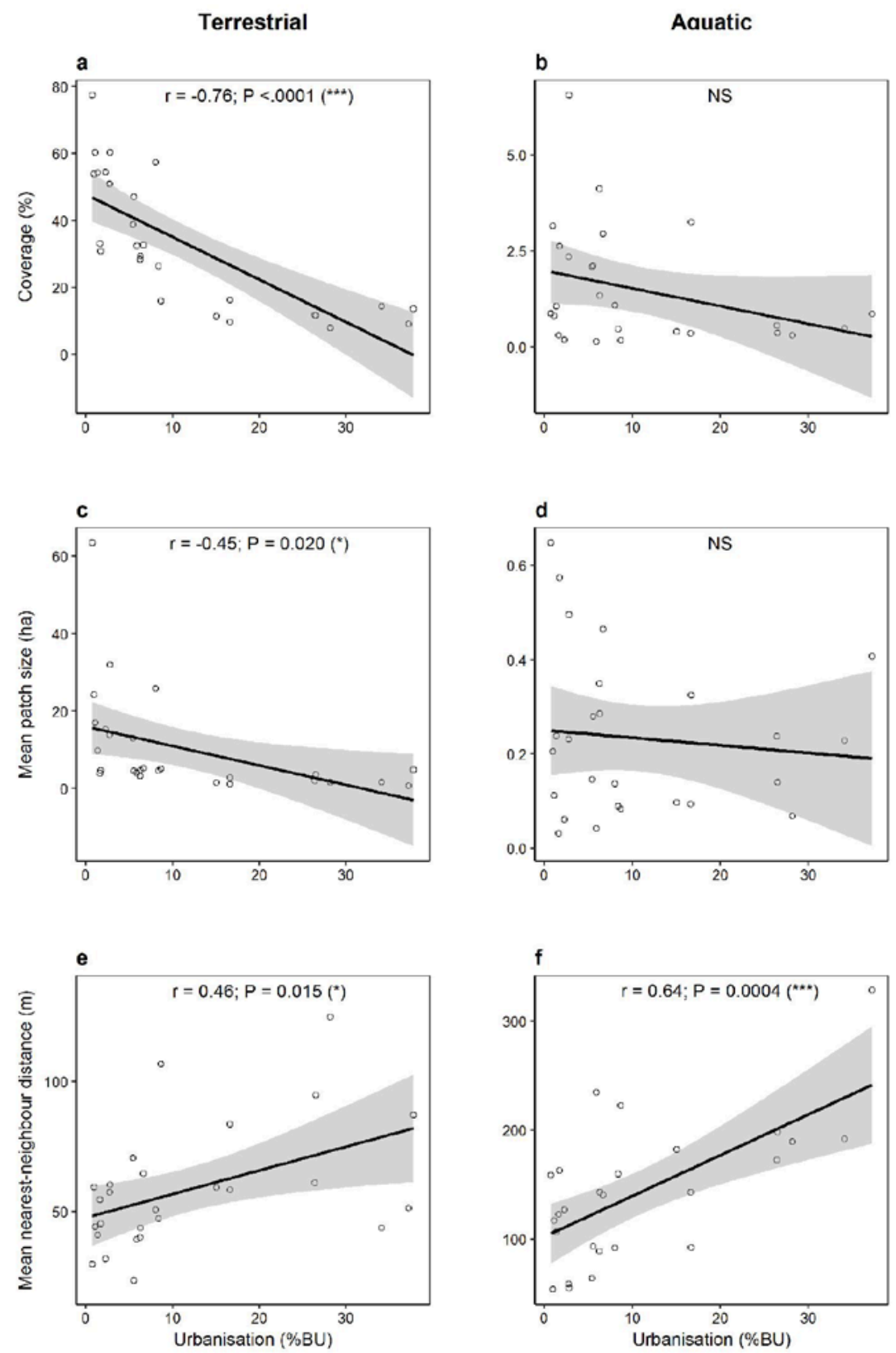


\section{Extended Data Table 1 Taxon-specific details of sampling procedures, body size data and size- dispersal links}

$N$, counted individuals; $S$, cumulative species richness.

Some of the sampling methods and data on body size and size-dispersal links are from previously published work ${ }^{39-56}$.

\begin{tabular}{|c|c|c|c|c|c|c|c|}
\hline Taxon & Sampling method & Sites & $N$ & $s$ & $\begin{array}{l}\text { Body size } \\
\text { (proxy) }(\mathrm{mm})\end{array}$ & Body size data & $\begin{array}{l}\text { Size- } \\
\text { dispersal link }\end{array}$ \\
\hline Butterflies & $\begin{array}{l}\text { Visual counts in grassland while walking } 20 \\
\text { minutes ('Pollard walk'/subplot, with occasional } \\
\text { netting and visual inspections; each site sampled } \\
\text { three times during July till early September 2014: } \\
\text { up to } 18 \text { sites/day (simultaneous sampling by } \\
\text { two researchers) }\end{array}$ & 81 & 4,413 & 23 & Forewing length & $\begin{array}{l}\text { Means }^{30} \text {, also for } \\
\text { sexually or } \\
\text { seasonally } \\
\text { dimorphic species }\end{array}$ & Positive $^{00-12}$ \\
\hline Macro-moths & $\begin{array}{l}\text { Full-night light-trapping with one Heath trap (6W) } \\
\text { at woodland; each site sampled } 11 \text { times during } \\
\text { August till early September } 2014 \text { and during } \\
\text { April, July and August 2015; four sites } \\
\text { simultaneously/night; identification of within-trap } \\
\text { samples during early mornings down to species- } \\
\text { level, except for Hoplodrina and Mesapamea sp. }\end{array}$ & 12 & 3,067 & 202 & Wing span & $\begin{array}{l}\text { Means }{ }^{43} \quad{ }^{+} \\
\text {www.lepidoptera.e } \\
\text { u), also for } \\
\text { sexually dimorphic } \\
\text { species; but males } \\
\text { only for three } \\
\text { species with } \\
\text { flightless females }\end{array}$ & Positive $^{12 / 2,45}$ \\
\hline Orthopterans & $\begin{array}{l}\text { Auditive counts in grassland of male } \\
\text { grasshoppers and bush crickets while walking } 20 \\
\text { minutes/subplot, with occasional visual } \\
\text { inspections; each site sampled three times } \\
\text { during July till early September 2014; up to } 18 \\
\text { sites/day (simultaneous sampling by two } \\
\text { researchers) }\end{array}$ & 81 & 10,302 & 8 & Body length & $\begin{array}{l}\text { Means (without } \\
\text { wings } \\
\text { appendages) }\end{array}$ & $\begin{array}{l}\text { Positive } \\
\text { (our subset) }\end{array}$ \\
\hline Web spiders & $\begin{array}{l}\text { Visual and complete exploration of subplots to } \\
\text { collect and store every individual in } 70 \% \text { ethanol } \\
\text { until identification via a microscope of all adult } \\
\text { specimens; three sites sampled/day during } \\
\text { September } 2014\end{array}$ & 62 & 2,456 & 18 & $\begin{array}{l}\text { Cephalothorax } \\
\text { width }\end{array}$ & $\begin{array}{lr}\begin{array}{l}\text { Means of } \\
\text { captured } \\
\text { spiders; } \\
\text { microscope- } \\
\text { measured }\end{array} \\
\end{array}$ & $\begin{array}{l}\begin{array}{l}\text { Neutral } \\
\text { (bell-shaped) }\end{array}\end{array}$ \\
\hline Ground spiders & $\begin{array}{l}\text { Pitfall trapping, simultaneously at all sites with } \\
\text { two pitfalls/site placed in grassy, open habitats } \\
\text { from April till August } 2013 \text {. Identification via } \\
\text { microscope of all adult specimens, stored in } 70 \% \\
\text { ethanol }\end{array}$ & 81 & 27,763 & 184 & Body length & $\begin{array}{l}\text { Values of females }{ }^{47} \\
\left(^{+}\right. \\
\text {www.araneae.unib } \\
\text { e.ch })\end{array}$ & $\begin{array}{l}\text { Neutral } \\
\text { (bell-shaped) }\end{array}$ \\
\hline Ground beetles & Identical to ground spider sampling & 81 & 7,604 & 128 & Body length & Means $^{48}$ & Neutral $^{22}$ \\
\hline Weevils & Identical to ground spider sampling & 78 & 2,600 & 73 & Body length & $\begin{array}{l}\text { Means of minimum } \\
+\quad \text { maximum }^{+} \text {malues } \\
\text { va }^{\text {end }}\end{array}$ & Neutral \\
\hline Rotifers & $\begin{array}{l}\text { Community sampling of bdelloid rotifers } \\
\text { recovered from dormancy four hours after } \\
\text { hydration of one Xanthoria lichen thalli of } 2.5 \mathrm{~cm}^{2} \\
\text { in a petri dish, a period known to recover all } \\
\text { dormant individuals; each site sampled once } \\
\text { during July 2013; up to } 18 \text { sites/day }\end{array}$ & 81 & 4,936 & 21 & Body length & $\begin{array}{l}\text { Maximum recorded } \\
\text { lengths in in } \\
\text { literature; mostly } \\
\text { from original } \\
\text { species } \\
\text { descriptions and }\end{array}$ & Neutral $^{51}$ \\
\hline Ostracods & $\begin{array}{l}\text { Handnet sampling in one pond/subplot at up to } \\
\text { nine ponds/day from mid-August till mid- } \\
\text { September } 2014 \text {. Individual ostracods were } \\
\text { sorted from the bulk sample under a microscope } \\
\text { to a minimum of } 50 \text { individuals, in cases where } \\
\text { ostracods were present. Rarefaction analyses } \\
\text { showed that the samples were representative for } \\
\text { the ostracod communities }\end{array}$ & 81 & 3,111 & 17 & Body length & Values of females ${ }^{52}$ & $\begin{array}{l}\text { Negative } \\
\text { neutra| }^{53.54}\end{array}$ \\
\hline Cladocerans & $\begin{array}{l}\text { Zooplankton sampling with tube sampler in one } \\
\text { pond/subplot, collecting } 5 \text { I water at each of eight } \\
\text { locations/pond, integrating the entire water } \\
\text { column from close to bottom till surface; } \\
\text { crustacean zooplankton for density assessment } \\
\text { is filtered through a } 64 \mathrm{~mm} \text { conical net; samples } \\
\text { are collected in } 60 \mathrm{ml} \text { vials and fixed with } \\
\text { formalin (2 } \mathrm{ml} \text { in } 48 \mathrm{ml} \text { of sample): min. } 300 \\
\text { individuals were identified/sample (Daphnia } \\
\text { longispina, D. galeata and } D \text {. hyalina were } \\
\text { combined in the } D \text {. longispina complex); } \\
\text { individual counts were volume-corrected for each } \\
\text { sample; } 15 \text { random individuals/species occurring } \\
\text { in each sample were measured (if less } \\
\text { individuals present/species, all were measured). } \\
\text { Sampling was conducted from } 29 \text { May till 10 July } \\
\text { 2013. Three ponds (one plot) were sampled/day, } \\
\text { with plot sampling randomized over the sampling } \\
\text { period. Detailed information }\end{array}$ & 81 & 28,749 & 28 & Body length & $\begin{array}{l}\text { Means (eye top till } \\
\text { tail spine base) of } \\
\text { up to } 15 \text { individuals } \\
\text { per species per } \\
\text { sample, with } \\
\text { Ceriodaphnia } \\
\text { values combined } \\
\text { into one category. } \\
\text { Means from all } \\
\text { ponds were } \\
\text { averaged further }\end{array}$ & $\begin{array}{l}\text { Negative } \\
\text { neutra| }\end{array}$ \\
\hline
\end{tabular}


Extended Data Table 2 | Model output of average temperature in relation to urbanization and habitat type

Output of linear mixed regression models that test the relationship between average local ambient temperatures and the interaction between percentage BUC (\%BU) and habitat type (pond, grassland and woodland) ( $n=104$ sites). Only the output for the confidence set of models ( $\triangle \mathrm{AICc} \leq 2)$ is given, with scale referring to the associated radius scale (in metres) of percentage BUC. Model estimates ( \pm s.e.m.) for percentage BUC regression coefficients are provided. Model output consistently shows clear temperature differences among habitats and a clear positive effect of urbanization on temperature, irrespective of habitat type (as shown by the non-significant interactions).

\begin{tabular}{|c|c|c|c|c|c|c|}
\hline & Scale & $\triangle \mathrm{AICc}$ & Fixed effect & $\chi^{2}$ test & $P$ value & Estimate \pm s.e.m. \\
\hline $\begin{array}{l}\text { Diurnal } \\
\text { summer }\end{array}$ & 50 & 0.00 & $\begin{array}{l}\text { BUC x Habitat } \\
\text { BUC } \\
\text { Habitat }\end{array}$ & $\begin{array}{l}\chi_{2}^{2}=4.05 \\
X_{1}^{2}=13.96 \\
X_{2}^{2}=39.67\end{array}$ & $\begin{array}{l}P=0.13 \\
P=0.0001 \\
P<0.0001\end{array}$ & $0.0655 \pm 0.0172$ \\
\hline \multirow[t]{2}{*}{$\begin{array}{l}\text { Nocturnal } \\
\text { summer }\end{array}$} & 50 & 0.00 & $\begin{array}{l}\text { BUC } \times \text { Habitat } \\
\text { BUC } \\
\text { Habitat }\end{array}$ & $\begin{array}{l}X^{2}{ }_{2}=2.73 \\
X^{2}{ }_{1}=17.66 \\
X^{2}{ }_{2}=82.37\end{array}$ & $\begin{array}{l}P=0.25 \\
P<0.0001 \\
P<0.0001\end{array}$ & $0.0706 \pm 0.0163$ \\
\hline & 100 & 0.91 & $\begin{array}{l}\text { BUC } \times \text { Habitat } \\
\text { BUC } \\
\text { Habitat }\end{array}$ & $\begin{array}{l}X^{2}{ }_{2}=0.14 \\
X^{2}{ }_{1}=16.76 \\
X^{2}{ }_{2}=83.19\end{array}$ & $\begin{array}{l}P=0.93 \\
P<0.0001 \\
P<0.0001\end{array}$ & $0.0579 \pm 0.0138$ \\
\hline $\begin{array}{l}\text { Diurnal } \\
\text { winter }\end{array}$ & 200 & 0.00 & $\begin{array}{l}\text { BUC } \times \text { Habitat } \\
\text { BUC } \\
\text { Habitat }\end{array}$ & $\begin{array}{l}X^{2}{ }_{2}=0.21 \\
X^{2}=10.15 \\
X^{2}{ }_{2}=5.45\end{array}$ & $\begin{array}{l}P=0.89 \\
P=0.001 \\
P=0.06\end{array}$ & $0.0221 \pm 0.0069$ \\
\hline \multirow[t]{2}{*}{$\begin{array}{l}\text { Nocturnal } \\
\text { winter }\end{array}$} & 400 & 0.00 & $\begin{array}{l}\text { BUC } \times \text { Habitat } \\
\text { BUC } \\
\text { Habitat }\end{array}$ & $\begin{array}{l}X^{2}{ }_{2}=0.21 \\
X^{2}{ }_{1}=10.94 \\
X^{2}{ }_{2}=76.57\end{array}$ & $\begin{array}{l}P=0.89 \\
P=0.0009 \\
P<0.0001\end{array}$ & $0.0227 \pm 0.0068$ \\
\hline & 800 & 1.33 & $\begin{array}{l}\text { BUC } \times \text { Habitat } \\
\text { BUC } \\
\text { Habitat }\end{array}$ & $\begin{array}{l}X^{2}{ }_{2}=0.39 \\
X^{2}{ }_{1}=9.61 \\
X^{2}{ }_{2}=77.55\end{array}$ & $\begin{array}{l}P=0.82 \\
P=0.0019 \\
P<0.0001\end{array}$ & $0.0213 \pm 0.0068$ \\
\hline
\end{tabular}


Extended Data Table 3 | Model output of CWMBS in relation to urbanization

Output of linear mixed regression models testing the relationship between CWMBS and percentage BUC at multiple scales (radii in metres), for ten taxa ( $n=76,12,75,80,62,60,81,81,68$ and 80 biologically independent communities, top to bottom). Confidence sets of models ( $\triangle \mathrm{AICc} \leq 2)$ have grey shading and the best-fitting model output is given in bold. Modelled intercepts and slopes ( \pm s.e.m.) are given. Credits for animal outlines are listed in the legend of Fig. 3.

\begin{tabular}{|c|c|c|c|c|c|c|}
\hline Taxon & Scale & $\Delta \mathrm{AICc}$ & $F$ test & $P$ value & Intercept & Slope \\
\hline \multirow{7}{*}{ Orthopterans } & 50 & 9.24 & $F_{1,61.0}=0.14$ & $P=0.71$ & $21.458 \pm 0.436$ & $0.015 \pm 0.040$ \\
\hline & 100 & 8.91 & $F_{1538}=0.48$ & $P=0.49$ & $21.370 \pm 0.457$ & $0.024 \pm 0.035$ \\
\hline & 200 & 6.83 & $F_{1.59 .9}=2.49$ & $P=0.12$ & $21.104 \pm 0.476$ & $0.052 \pm 0.033$ \\
\hline & 400 & 8.29 & $F_{1,73.9}=1.01$ & $P=0.32$ & $21.203 \pm 0.502$ & $0.035 \pm 0.034$ \\
\hline & 800 & 7.85 & $F_{1,55.0}=1.43$ & $P=0.24$ & $21.084 \pm 0.527$ & $0.047 \pm 0.038$ \\
\hline & 1,600 & 5.67 & $F_{1,34.1}=3.64$ & $P=0.065$ & $20.752 \pm 0.548$ & $0.081 \pm 0.042$ \\
\hline & 3,200 & 0.00 & $F_{1,26.7}=10.46$ & $P=0.0032$ & $20.122 \pm 0.549$ & $0.171 \pm 0.053$ \\
\hline \multirow{7}{*}{ Macro-moths } & 50 & 10.14 & $F_{18.6}=1.72$ & $P=0.22$ & $38.883 \pm 1.293$ & $0.227 \pm 0.148$ \\
\hline & 100 & 7.70 & $F_{1,7.0}=4.26$ & $P=0.078$ & $37.949 \pm 1.336$ & $0.282 \pm 0.123$ \\
\hline & 200 & 3.98 & $F_{1,9.1}=7.64$ & $P=0.022$ & $36.721 \pm 1.245$ & $0.335 \pm 0.103$ \\
\hline & 400 & 3.04 & $F_{174}=8.96$ & $P=0.019$ & $36.886 \pm 1.140$ & $0.306 \pm 0.087$ \\
\hline & 800 & 0.00 & $F_{1,4.6}=16.84$ & $P=0.011$ & $36.566 \pm 1.016$ & $0.303 \pm 0.070$ \\
\hline & 1,600 & 2.78 & $F_{1,4.1}=12.41$ & $P=0.023$ & $36.889 \pm 1.122$ & $0.273 \pm 0.076$ \\
\hline & 3,200 & 4.57 & $F_{1,4.0}=9.57$ & $P=0.036$ & $36.996 \pm 1.227$ & $0.319 \pm 0.103$ \\
\hline \multirow{7}{*}{ Rotifers } & 50 & 1.08 & $F_{1,70.9}=0.55$ & $P=0.46$ & $0.456 \pm 0.021$ & $0.002 \pm 0.002$ \\
\hline & 100 & 1.24 & $F_{1,67.5}=0.41$ & $P=0.52$ & $0.457 \pm 0.022$ & $0.001 \pm 0.002$ \\
\hline & 200 & 0.23 & $F_{1,72.1}=1.35$ & $P=0.25$ & $0.447 \pm 0.023$ & $0.002 \pm 0.002$ \\
\hline & 400 & 0.00 & $F_{1,53.9}=1.55$ & $P=0.22$ & $0.446 \pm 0.022$ & $0.002 \pm 0.002$ \\
\hline & 800 & 0.69 & $F_{1,37.2}=0.92$ & $P=0.34$ & $0.450 \pm 0.023$ & $0.002 \pm 0.002$ \\
\hline & 1,600 & 0.36 & $F_{1,27.5}=1.26$ & $P=0.27$ & $0.447 \pm 0.024$ & $0.002 \pm 0.002$ \\
\hline & 3,200 & 0.81 & $F_{1,23.2}=0.84$ & $P=0.37$ & $0.449 \pm 0.025$ & $0.002 \pm 0.002$ \\
\hline \multirow{7}{*}{ Butterflies } & 50 & 0.41 & $F_{1,71.2}=7.25$ & $P=0.0088$ & $22.637 \pm 0.230$ & $0.068 \pm 0.025$ \\
\hline & 100 & 0.00 & $F_{1,59.6}=7.53$ & $P=0.0080$ & $22.546 \pm 0.257$ & $0.060 \pm 0.022$ \\
\hline & 200 & 1.49 & $F_{1,66.2}=6.27$ & $P=0.015$ & $22.511 \pm 0.285$ & $0.050 \pm 0.020$ \\
\hline & 400 & 6.50 & $F_{1,77.5}=1.10$ & $P=0.30$ & $22.720 \pm 0.308$ & $0.022 \pm 0.020$ \\
\hline & 800 & 7.45 & $F_{1,53.8}=0.05$ & $P=0.82$ & $22.885 \pm 0.318$ & $0.005 \pm 0.022$ \\
\hline & 1,600 & 7.17 & $F_{1,33,4}=0.27$ & $P=0.61$ & $23.063 \pm 0.332$ & $-0.013 \pm 0.024$ \\
\hline & 3,200 & 7.39 & $F_{1277}=0.07$ & $P=0.80$ & $23.007 \pm 0.360$ & $-0.008 \pm 0.032$ \\
\hline \multirow{7}{*}{ Web spiders } & 50 & 0.14 & $F_{1.46 .5}=0.96$ & $P=0.33$ & $3.133 \pm 0.067$ & $-0.003 \pm 0.003$ \\
\hline & 100 & 0.83 & $F_{1,42.7}=0.32$ & $P=0.58$ & $3.128 \pm 0.073$ & $-0.002 \pm 0.004$ \\
\hline & 200 & 0.83 & $F_{1,47.2}=0.31$ & $P=0.58$ & $3.131 \pm 0.076$ & $-0.003 \pm 0.005$ \\
\hline & 400 & 0.76 & $F_{1,59.6}=0.35$ & $P=0.56$ & $3.138 \pm 0.081$ & $-0.003 \pm 0.005$ \\
\hline & 800 & 0.93 & $F_{1,48.7}=0.19$ & $P=0.66$ & $3.134 \pm 0.087$ & $-0.002 \pm 0.005$ \\
\hline & 1,600 & 1.08 & $F_{1,28.7}=0.05$ & $P=0.82$ & $3.124 \pm 0.093$ & $-0.002 \pm 0.006$ \\
\hline & 3,200 & 0.00 & $F_{1,22.3}=1.06$ & $P=0.31$ & $3.190 \pm 0.101$ & $-0.009 \pm 0.008$ \\
\hline \multirow{7}{*}{ Ostracods } & 50 & 3.03 & $F_{1,57.0}=0.00$ & $P=0.97$ & $-0.202 \pm 0.016$ & $-0.002 \pm 0.062$ \\
\hline & 100 & 2.72 & $F_{1,57.2}=0.27$ & $P=0.60$ & $-0.194 \pm 0.019$ & $-0.031 \pm 0.058$ \\
\hline & 200 & 2.09 & $F_{1,58.0}=0.88$ & $P=0.35$ & $-0.186 \pm 0.020$ & $-0.053 \pm 0.055$ \\
\hline & 400 & 1.19 & $F_{1,51.4}=1.71$ & $P=0.20$ & $-0.179 \pm 0.020$ & $-0.075 \pm 0.055$ \\
\hline & 800 & 0.89 & $F_{1,43.5}=1.98$ & $P=0.17$ & $-0.176 \pm 0.021$ & $-0.084 \pm 0.058$ \\
\hline & 1,600 & 0.00 & $F_{1,32.2}=2.83$ & $P=0.10$ & $-0.168 \pm 0.022$ & $-0.113 \pm 0.066$ \\
\hline & 3,200 & 0.22 & $F_{1,26.8}=2.67$ & $P=0.11$ & $-0.160 \pm 0.027$ & $-0.148 \pm 0.089$ \\
\hline \multirow{7}{*}{ Ground spiders } & 50 & 7.95 & $F_{1,69.6}=5.07$ & $P=0.028$ & $4.993 \pm 0.113$ & $-0.027 \pm 0.012$ \\
\hline & 100 & 0.00 & $F_{1,60.0}=13.82$ & $P=0.0004$ & $5.116 \pm 0.116$ & $-0.036 \pm 0.010$ \\
\hline & 200 & 2.81 & $F_{1,71.6}=9.83$ & $P=0.0025$ & $5.127 \pm 0.122$ & $-0.029 \pm 0.009$ \\
\hline & 400 & 5.30 & $F_{1,72.5}=6.92$ & $P=0.010$ & $5.113 \pm 0.127$ & $-0.024 \pm 0.009$ \\
\hline & 800 & 5.40 & $F_{1,46.3}=6.86$ & $P=0.012$ & $5.123 \pm 0.130$ & $-0.025 \pm 0.009$ \\
\hline & 1,600 & 6.80 & $F_{1,31,2}=5.57$ & $P=0.025$ & $5.110 \pm 0.134$ & $-0.023 \pm 0.010$ \\
\hline & 3,200 & 7.23 & $F_{126.9}=5.34$ & $P=0.029$ & $5.124 \pm 0.139$ & $-0.029 \pm 0.013$ \\
\hline \multirow{7}{*}{ Ground beetles } & 50 & 7.17 & $F_{1,75.2}=2.02$ & $P=0.16$ & $8.646 \pm 0.276$ & $-0.047 \pm 0.032$ \\
\hline & 100 & 3.66 & $F_{1,64,4}=5.57$ & $P=0.021$ & $8.894 \pm 0.294$ & $-0.069 \pm 0.029$ \\
\hline & 200 & 1.79 & $F_{1,76.5}=7.39$ & $P=0.0081$ & $9.045 \pm 0.310$ & $-0.071 \pm 0.025$ \\
\hline & 400 & 1.58 & $F_{1,65.8}=7.44$ & $P=0.0082$ & $9.080 \pm 0.319$ & $-0.066 \pm 0.023$ \\
\hline & 800 & 0.00 & $F_{1,41,4}=9.19$ & $P=0.0042$ & $9.152 \pm 0.318$ & $-0.071 \pm 0.023$ \\
\hline & 1,600 & 1.39 & $F_{1,29,7}=7.94$ & $P=0.0085$ & $9.124 \pm 0.326$ & $-0.068 \pm 0.024$ \\
\hline & 3,200 & 5.51 & $F_{1,26.7}=3.70$ & $P=0.065$ & $8.976 \pm 0.360$ & $-0.063 \pm 0.033$ \\
\hline \multirow{7}{*}{ Weevils } & 50 & 4.20 & $F_{1557}=2.02$ & $P=0.16$ & $4.170 \pm 0.178$ & $-0.024 \pm 0.017$ \\
\hline & 100 & 0.00 & $F_{1,48.1}=6.59$ & $P=0.013$ & $4.323 \pm 0.190$ & $-0.037 \pm 0.014$ \\
\hline & 200 & 2.21 & $F_{1.56 .5}=3.92$ & $P=0.053$ & $4.309 \pm 0.200$ & $-0.028 \pm 0.014$ \\
\hline & 400 & 2.37 & $F_{1,66.0}=3.71$ & $P=0.059$ & $4.330 \pm 0.210$ & $-0.027 \pm 0.013$ \\
\hline & 800 & 3.65 & $F_{1,50.8}=2.51$ & $P=0.12$ & $4.308 \pm 0.223$ & $-0.024 \pm 0.014$ \\
\hline & 1,600 & 5.20 & $F_{1,32,2}=0.99$ & $P=0.33$ & $4.230 \pm 0.236$ & $-0.017 \pm 0.016$ \\
\hline & 3,200 & 5.68 & $F_{1,26.5}=0.51$ & $P=0.48$ & $4.193 \pm 0.251$ & $-0.016 \pm 0.022$ \\
\hline \multirow{7}{*}{ Cladocerans } & 50 & 0.00 & $F_{1,70.7}=12.37$ & $P=0.0008$ & $-0.164 \pm 0.037$ & $-0.010 \pm 0.003$ \\
\hline & 100 & 0.32 & $F_{1769}=12.72$ & $P=0.0006$ & $-0.141 \pm 0.042$ & $-0.009 \pm 0.003$ \\
\hline & 200 & 4.48 & $F_{1,73.6}=8.74$ & $P=0.0042$ & $-0.156 \pm 0.044$ & $-0.007 \pm 0.002$ \\
\hline & 400 & 5.35 & $F_{1.63 .8}=7.82$ & $P=0.0068$ & $-0.160 \pm 0.044$ & $-0.007 \pm 0.002$ \\
\hline & 800 & 8.69 & $F_{1,45.1}=3.67$ & $P=0.062$ & $-0.186 \pm 0.044$ & $-0.005 \pm 0.003$ \\
\hline & 1,600 & 10.37 & $F_{1,31.1}=1.68$ & $P=0.20$ & $-0.204 \pm 0.044$ & $-0.004 \pm 0.003$ \\
\hline & 3,200 & 10.73 & $F_{1,26.6}=1.19$ & $P=0.29$ & $-0.204 \pm 0.048$ & $-0.005 \pm 0.004$ \\
\hline
\end{tabular}




\section{Extended Data Table 4 | Model output of abundance and diversity measures in relation to urbanization}

Output of linear mixed regression models for ten taxa $(n=76,12,75,80,62,60,81,81,68$ and 80 biologically independent communities, top to bottom), testing the relationship between abundance $(N)$ and two diversity measures (species richness $(S)$ and Shannon index $(H)$ ) and percentage BUC at the spatial scale (radius in metres) providing the best-fitting models. $t$ indicates that $\log (x+1)$

transformations improved residual fits. Modelled (back-transformed) percentage change across a 0 $25 \%$ BUC gradient is also given. Credits for animal outlines are listed in the legend of Fig. 3.

\begin{tabular}{|c|c|c|c|c|c|}
\hline Taxon & $\mathrm{N} / \mathrm{S} / \mathrm{H}$ & Scale & $F$ test & $P$ value & $\begin{array}{l}\% \text { change } \\
0-25 \% \text { BUC }\end{array}$ \\
\hline \multirow{3}{*}{ Orthopterans } & $\mathrm{t} N$ & 200 & $F_{1,66.2}=20.58$ & $P<0.0001$ & -82.9 \\
\hline & $S$ & 400 & $F_{1,78.5}=16.24$ & $P=0.0001$ & -34.5 \\
\hline & $H$ & 400 & $F_{1,63.0}=0.68$ & $P=0.41$ & -8.4 \\
\hline \multirow{3}{*}{ Macro-moths } & $\mathrm{t} N$ & 3,200 & $F_{1,4.0}=52.6$ & $P=0.0019$ & -89.2 \\
\hline & $\mathrm{t} S$ & 3,200 & $F_{1,4.0}=108.1$ & $P=0.0005$ & -82.7 \\
\hline & $H$ & 800 & $F_{1,5.2}=55.8$ & $P=0.0006$ & -43.5 \\
\hline \multirow{3}{*}{ Rotifers } & $\mathrm{t} N$ & 400 & $F_{1,67,1}=2.1$ & $P=0.15$ & +108.1 \\
\hline & $\mathrm{t} S$ & 400 & $F_{1,67.9}=0.4$ & $P=0.53$ & +15.6 \\
\hline & $H$ & 3,200 & $F_{1,37.9}=1.2$ & $P=0.28$ & +38.8 \\
\hline \multirow{3}{*}{ Butterflies } & $\mathrm{t} N$ & 200 & $F_{1,71.4}=42.1$ & $P<0.0001$ & -85.3 \\
\hline & $S$ & 200 & $F_{1,69.7}=54.2$ & $P<0.0001$ & -59.1 \\
\hline & $H$ & 200 & $F_{1,75.8}=7.3$ & $P=0.0085$ & -22.5 \\
\hline \multirow{3}{*}{ Web spiders } & $\mathrm{t} N$ & 200 & $F_{1,54,1}=7.9$ & $P=0.0069$ & -18.3 \\
\hline & $\mathrm{t} S$ & 200 & $F_{1,53.8}=15.1$ & $P=0.0003$ & -29.2 \\
\hline & $\mathrm{t} H$ & 200 & $F_{1,54.0}=12.3$ & $P=0.0009$ & -21.1 \\
\hline \multirow{3}{*}{ Ostracods } & $\mathrm{t} N$ & 50 & $F_{1,71.1}=3.6$ & $P=0.06$ & -69.2 \\
\hline & $\mathrm{t} S$ & 50 & $F_{1,71.3}=2.1$ & $P=0.15$ & -38.6 \\
\hline & $H$ & 1,600 & $F_{1,35.1}=2.2$ & $P=0.15$ & -41.2 \\
\hline \multirow{3}{*}{ Ground spiders } & $N$ & 100 & $F_{1,65.1}=5.7$ & $P=0.020$ & -43.6 \\
\hline & $S$ & 800 & $F_{1,43.3}=2.3$ & $P=0.14$ & -13.4 \\
\hline & $H$ & 3,200 & $F_{1,26.6}=12.3$ & $P=0.0016$ & -20.3 \\
\hline \multirow{3}{*}{ Ground beetles } & $\mathrm{t} N$ & 800 & $F_{1,47.2}=5.8$ & $P=0.020$ & -50.7 \\
\hline & $\mathrm{t} S$ & 800 & $F_{1,44.3}=11.9$ & $P=0.0013$ & -39.9 \\
\hline & $\mathrm{t} H$ & 200 & $F_{1,76.9}=11.5$ & $P=0.0011$ & -21.9 \\
\hline \multirow{3}{*}{ Weevils } & $\mathrm{t} N$ & 100 & $F_{1,56.9}=12.0$ & $P=0.0010$ & +547.9 \\
\hline & $\mathrm{t} S$ & 100 & $F_{1,56.8}=4.5$ & $P=0.038$ & +99.2 \\
\hline & $\mathrm{t} H$ & 400 & $F_{1,63.9}=0.7$ & $P=0.40$ & +25.0 \\
\hline \multirow{3}{*}{ Cladocerans } & $\mathrm{t} N$ & 3,200 & $F_{1,27.2}=1.2$ & $P=0.29$ & -68.5 \\
\hline & $S$ & 200 & $F_{1,62.8}=1.1$ & $P=0.29$ & +12.7 \\
\hline & $H$ & 3,200 & $F_{1,26.2}=0.2$ & $P=0.65$ & -11.4 \\
\hline
\end{tabular}

